\title{
Effect of temperature on the maintenance and termination of diapause in overwintering females of Pseudaulacaspis pentagona (Hemiptera: Diaspididae)
}

\author{
Mitsuyoshi TAKEDA ${ }^{\dagger}$ \\ National Institute of Vegetable and Tea Science; Shimada 428-8501, Japan
}

(Received 18 August 2005; Accepted 7 April 2006)

\begin{abstract}
Overwintering females of Pseudaulacaspis pentagona (Targioni-Tozetti) entered reproductive diapause, and the ovarian development in females collected before the end of the year was retarded, but development proceeded normally after the beginning of the year. I examined the effects of temperature on the maintenance and termination of diapause in overwintering females that were reared on pumpkin fruits under natural conditions and then transferred to laboratory conditions. Reproductive diapause was averted by a high temperature of $25^{\circ} \mathrm{C}$, irrespective of the time of transfer. In contrast, temperatures of 22.5 and $20^{\circ} \mathrm{C}$ maintained the diapause when the overwintering females were transferred before the winter solstice. Reproductive diapause gradually terminated at a temperature of $17.5^{\circ} \mathrm{C}$. Diapause development proceeded when females were reared at $15^{\circ} \mathrm{C}$, and in early to mid-February the females began to lay eggs in the samples transferred between November and January. Diapausing females continuously fed on the pumpkin fruits and added secretory materials to the scale cover after being transferred to the incubators. The scale cover, which became thick during diapause, might protect the insect against adverse environmental conditions.
\end{abstract}

Key words: Pseudaulacaspis pentagona; reproductive diapause; temperature; diapause development

\section{INTRODUCTION}

The mulberry scale, Pseudaulacaspis pentagona (Targioni-Tozetti) (Hemiptera: Diaspididae), is a destructive and polyphagous insect (Hanks and Denno, 1993) that is the main pest of tea plants in Japan (Kawai et al., 1997). In most tea-cultivating areas of Japan, $P$. pentagona has three generations a year, but its voltinism fluctuates from two to three generations a year depending on the regional climate (Shinano et al., 1976). The mulberry scale only lives inside tea bushes, and the effective period for pesticide application is very short, $2-5 \mathrm{~d}$ after the peak of hatching (Tatara, 1999). In a previous paper, I described the timing of oviposition and egg hatching under laboratory and field conditions, and also presented logistic equations describing the sequence of oviposition and hatching in nature (Takeda, 2004). Adult females of $P$. pentagona overwinter after copulation, and the overwintering females have undeveloped ovarian eggs (Yasuda, 1981). I also showed that $P$. pentagona enter repro- ductive diapause with undeveloped ovarian eggs (Takeda, 2004). The reproductive diapause phase ends around the end of the year under natural conditions, and cannot be terminated by either long or short photoperiods at $20^{\circ} \mathrm{C}$ when females are collected before the winter solstice (Takeda, 2004). Diapause termination is a key life history factor, and January 1 is employed as the starting date of the day-degree accumulations for the optimum timing of chemical application to control first-generation larvae (Takeda, 2004).

For a very large number of insects from temperate regions, a period of low temperatures allows diapause development to be completed (Danks, 1987). Recently, it has been shown that an increasing number of species complete diapause without chilling (Nomura and Ishikawa, 2000). I conducted this study to elucidate the effect of temperature on the maintenance and termination of reproductive diapause.

\footnotetext{
† Present address: National Institute of Vegetable and Tea Science, Tsu 514-2392, Japan. E-mail: takedada@affrc.go.jp DOI: $10.1303 / \mathrm{aez} .2006 .429$
} 


\section{MATERIALS AND METHODS}

Effects of temperature on ovarian development and oviposition in overwintering females reared on pumpkin fruits. I collected tea branches infested with second-generation females from a tea field of the National Institute of Vegetable and Tea Science (NIVT, $138^{\circ} 08^{\prime} 09^{\prime \prime} \mathrm{E}$, $34^{\circ} 48^{\prime} 15^{\prime \prime} \mathrm{N}, 210 \mathrm{~m}$ altitude) on September 14 and 15,2000 . The female's cover was pealed away using pointed tweezers under a binocular microscope to check for oviposition, and eggs under the female's cover were collected. The eggs collected from the covers of about 15 females were placed on a pumpkin fruit in a screened house $(n=30)$, and the pumpkin fruits were covered with black cheesecloth for shading and for protection against parasitoids. The third-generation females were transferred to incubators at 15, 17.5, 20, 22.5 and $25^{\circ} \mathrm{C}$ under long day (15L : 9D) conditions on November 22, December 6, December 14, December 21, and December 28, 2000, and on January 4, 2001. Then about 25 to 30 females in each treatment were checked for the development of ovarian eggs and oviposition at intervals of about $7 \mathrm{~d}$. The females were removed and dissected in a physiological saline solution, and the developmental stages of the eggs in their ovaries were determined under a binocular microscope. The development of ovarian eggs was categorized into five stages (Yasuda, 1981) based on the following criteria: (1) egg cell and nutritional cell not distinguishable, (2) egg cell clearly distinguished from the nutritional cell, (3) egg cell bigger than the nutritional cell, and the ovarian egg being gourd-shaped, (4) egg cell having nearly absorbed the nutritional cell, and (5) ovarian eggs that have nearly developed their egg shells. Females having no developed ovarian eggs in the third stage, or a more advanced stage were regarded to be in diapause (Takeda, 2004). This observation was continued until the females were $a b-$ sent or the pumpkin fruits became rotten.

Predicting diapause termination under natural conditions. The meteorological data were recorded by the Meteorological Monitoring System in Kanaya (MMS-KANAYA; the instruments used for measurements were authorized by the Japan Meteorological Agency), located at NIVT. To check the response of the females reared on pumpkin fruits to temperature in a screened house, the daily mean temperature was used to calculate the effective temperature for the egg and gross larval stages. The developmental thresholds and effective temperatures for the egg and gross larval stage in $P$. pentagona were 12.3 and $10.3^{\circ} \mathrm{C}, 46.9$ and 383.0 degree-days (Park and Kim, 1990), respectively. The daily mean temperature was also used to evaluate the thermal conditions before each time the females were transferred in the screened house.

Effects of transfer time and temperature on the weight of the scale covering. To elucidate the effect of diapause duration and temperature on the weight of the scale cover, I collected the covers from 20 females at each observation of ovarian development for females reared on pumpkin fruits, and at the time of transfer to laboratory conditions on November 22 and December 21. The samples were also collected when the females were transferred to 15 and $17.5^{\circ} \mathrm{C}$ on December 28 and to 20 and $22.5^{\circ} \mathrm{C}$ on January 4 , respectively. After drying for $2 \mathrm{mo}$ in an oven at $50^{\circ} \mathrm{C}$, the covers from the 20 females were weighed in mass. Linear regression was used to fit a straight line to the data for the weights of the 20 scale covers and after logarithmic transformation of the rearing time in incubators.

\section{RESULTS}

Effects of temperature on ovarian development and oviposition in overwintering females reared on pumpkin fruits

The females that were transferred to $25^{\circ} \mathrm{C}$ on November 22 and December 6 gradually developed to the third stage or a more advanced stage of ovarian development, and some of them started laying eggs (Fig. 1). The percentages of diapause decreased rapidly when the females were transferred to $25^{\circ} \mathrm{C}$ on December 14 and 21, and most females started to lay eggs. In contrast, most of the ovarian eggs of the females that were transferred to 22.5 and $20^{\circ} \mathrm{C}$ on November 22 and December 6 remained in the second stage until the end of the observations. Thus, winter diapause was maintained at 22.5 and $20^{\circ} \mathrm{C}$ in the samples that had been transferred on the November and early December dates. The percentages of diapause among the samples transferred on December 14 were 48.5 to 75.9 (mean $63.5 \%$ ) and 51.7 to 72.0 (mean $71.5 \%$ ) at 22.5 and $20^{\circ} \mathrm{C}$, respectively, during the observations from January to March. When the females 

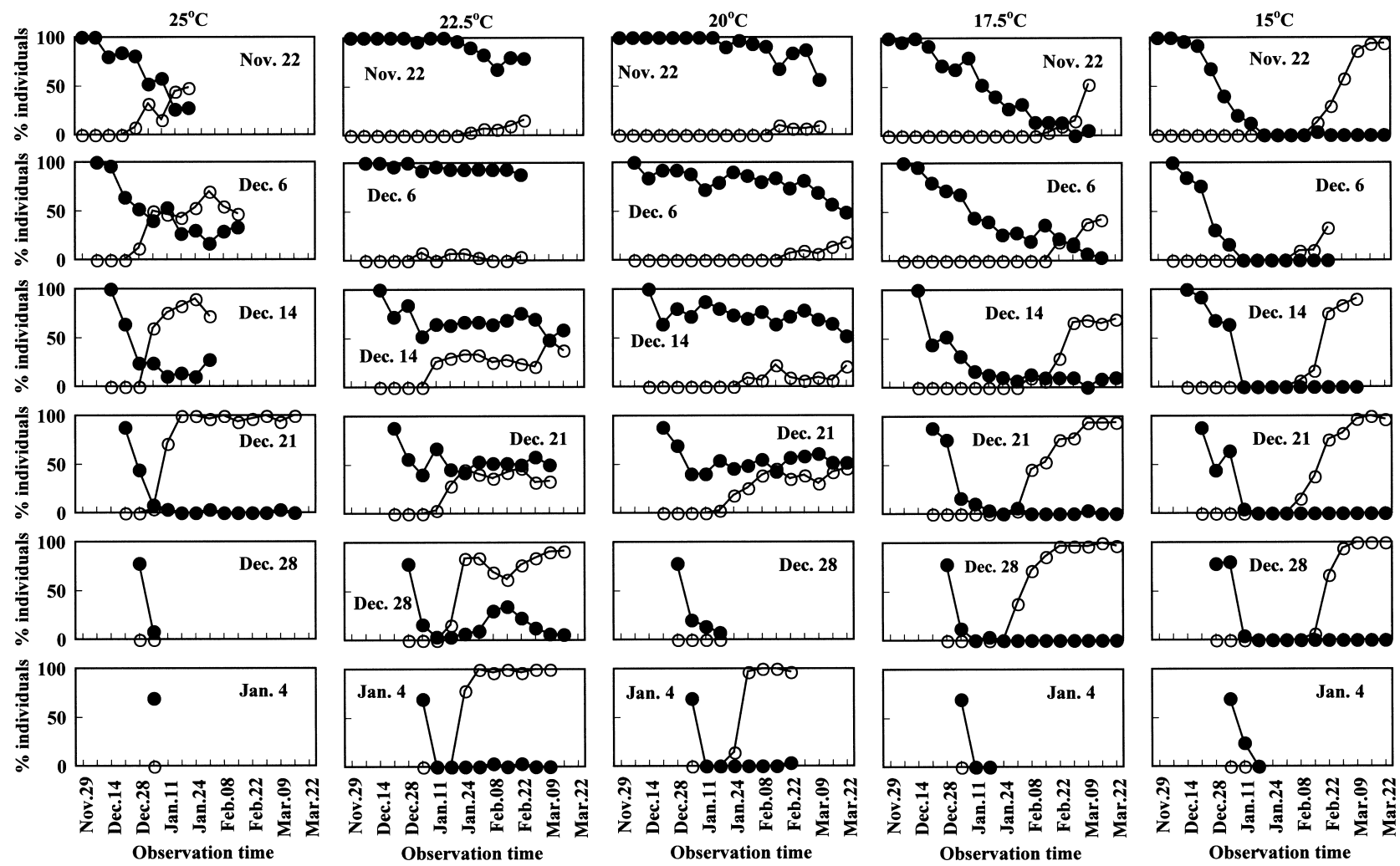

Fig. 1. The effects of temperature and time of transfer on the percentages of diapause and parous $P$. pentagona females reared on pumpkin fruits. Dates on the panels show the transfer time from natural conditions. Closed symbols show diapausing females with undeveloped ovarian eggs. Open symbols represent parous females. Sample sizes for each observation time of the cohort reared at $25,22.5,20,17.5$ and $15^{\circ} \mathrm{C}$ are 25-36 (mean 27.6), 18-44 (mean 29.6), 23-37 (mean 29.6), 19-38 (mean 29.2) and 25-35 (mean 28.7), respectively.

were transferred to 22.5 and $20^{\circ} \mathrm{C}$ on December 21 , the percentages of diapause ranged from 40.0 to $66.7 \%$ (mean $50.8 \%$ ) and 40.0 to $60.6 \%$ (mean $50.3 \%$ ), respectively. However, the diapause percentages decreased rapidly in the samples transferred to 22.5 and $20^{\circ} \mathrm{C}$ on December 28 and January 4 , and the remainder started laying eggs.

The effects of lower temperatures and time of transfer on diapause are also shown in Fig. 1. The diapause percentages in the samples of the transfer on November 22 and December 6 at $17.5^{\circ} \mathrm{C}$ decreased gradually. Those transferred on December 21 and 28 rapidly decreased, and most began to lay eggs from late January to March. In contrast, diapause in the females that were reared at $15^{\circ} \mathrm{C}$ was terminated regardless of the transfer time. More than $50 \%$ of the females transferred on November 22 began to lay eggs in the samples between February 21 and 28. For the samples of December 14, 21 and 28, egg laying began between February 15 and 22 , and the curves of the parous females were al- most the same.

\section{Predicting diapause termination under natural conditions}

To estimate the temperature experienced before being transferred to the incubators, the mean temperatures from September to December are shown in Fig. 2. The third-generation eggs of P. pentagona were placed on pumpkin fruits on September 14 and 15 , and some of them had already hatched by this time. The effective temperature for the gross larval stage (383 degree-days) was reached on October 23-24 and October 31-November 1, including the egg stage (46.9 degree-days). Thus, the tested insects grew to the adult stage from the end of October to the beginning of November. Therefore, the females transferred on November 22 experienced the mean daily temperature from November 1 to 22 , which ranged from 10.4 to $22.9^{\circ} \mathrm{C}$ (average $14.8^{\circ} \mathrm{C}$ ). Those transferred on December $6,14,21$ and 28 experienced mean daily tempera- 


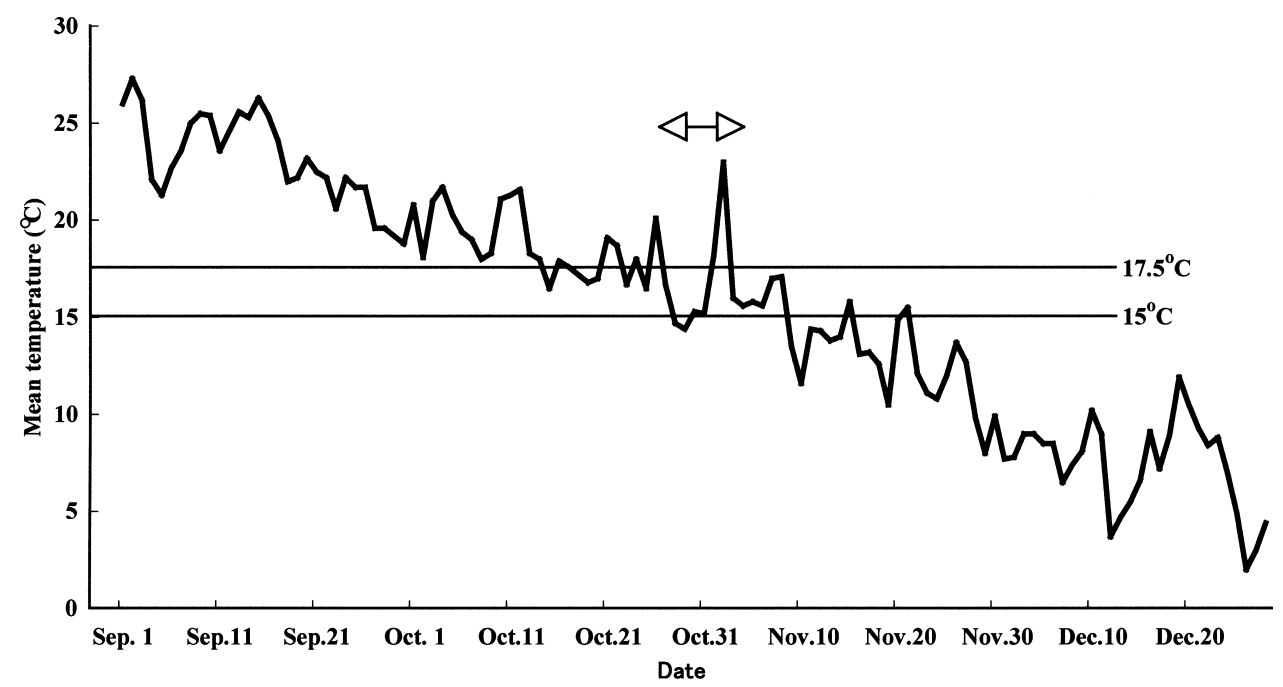

Fig. 2. Mean daily temperatures for the study site (NIVT, $138^{\circ} 08^{\prime} 09^{\prime \prime} \mathrm{E}, 34^{\circ} 48^{\prime} 15^{\prime \prime} \mathrm{N}, 210 \mathrm{~m}$ altitude), between September 1 and December 31,2000. An arrow indicates the period when the tested insects grew to the adult stage by calculating the effective temperature for the egg (46.9 degree-days) and gross larval stages (383 degree-days).

tures ranging from 7.7 to $13.6^{\circ} \mathrm{C}$ (average $9.8^{\circ} \mathrm{C}$ ), 3.6 to $10.1^{\circ} \mathrm{C}\left(6.8^{\circ} \mathrm{C}\right), 6.5$ to $11.8^{\circ} \mathrm{C}\left(9.0^{\circ} \mathrm{C}\right)$ and 1.9 to $8.7\left(5.4^{\circ} \mathrm{C}\right)$, respectively. Thus, the females reared on pumpkin fruits in the screened house were exposed to temperatures lower than $15^{\circ} \mathrm{C}$.

\section{Effects of the transfer time and temperature on the weight of the scale covering}

Most diapausing females transferred to the incubators on November 22 continued to feed on pumpkin fruits, and the weight of the scale covers increased as rearing time increased (Fig. 3). The samples transferred to $15,17.5^{\circ} \mathrm{C}$ on December 21 , 28 and to $20^{\circ} \mathrm{C}$ on December 21 and January 4 also showed a significant correlation $(p<0.05)$ between the weight of the scale cover and the rearing time. In contrast, there was no significant correlation $(p>0.05)$ between these parameters for the samples transferred to $22.5^{\circ} \mathrm{C}$ on December 21 and January 4, and to $25^{\circ} \mathrm{C}$ on December 21 .

\section{DISCUSSION}

In an earlier study (Takeda, 2004), reproductive diapause in $P$. pentagona was maintained under both long (15L:9D) and short (10L:14D) photoperiods when the females were transferred to a temperature of $20^{\circ} \mathrm{C}$ before the winter solstice. $P$. pentagona showed a progressive loss in sensitivity to temperature as diapause proceeded, and diapause was terminated in most females by the end of the year under natural conditions. The results of this study support the conclusion that temperature has the most significant effect on diapause termination in $P$. pentagona.

A temperature of $25^{\circ} \mathrm{C}$ averted or ended diapause even in the samples transferred on November 22, and some of $P$. pentagona started to lay eggs (Fig. 1). However, diapause was maintained at 22.5 and $20^{\circ} \mathrm{C}$, and terminated at $15^{\circ} \mathrm{C} \mathrm{(Fig.} \mathrm{1).} \mathrm{The} \mathrm{dia-}$ pause durations in the samples from November and early December were longer at $17.5^{\circ} \mathrm{C}$ than those at $15^{\circ} \mathrm{C}$ (Fig. 1). Thus, $17.5^{\circ} \mathrm{C}$ is the critical temperature between the maintenance and termination of diapause. At $15^{\circ} \mathrm{C}$, the females began to lay eggs at the same time regardless of the time of transfer (Fig. 1). Although the samples reared in the screened house experienced low temperatures ranging from 1.9 to $13.6^{\circ} \mathrm{C}$ from November 22 to December 28 (Fig. 2), the curves of the percentages of diapause and parous females at $15^{\circ} \mathrm{C}$ were almost the same (Fig. 1). This suggests that the temperature for diapause development is around $15^{\circ} \mathrm{C}$ or below, where diapause can be completed without chilling. The hatching of eggs in the third generation continues for 3-4wk (Tatara, 1999). The early-hatched larvae reach the adult stage in late October, and their diapause is maintained by intermediate temperatures ranging from 17.5 to $15^{\circ} \mathrm{C}$. Late hatching larvae emerge in early to midNovember and encounter diapause-terminating temperatures below $15^{\circ} \mathrm{C}$ after emergence (Fig. 2). 

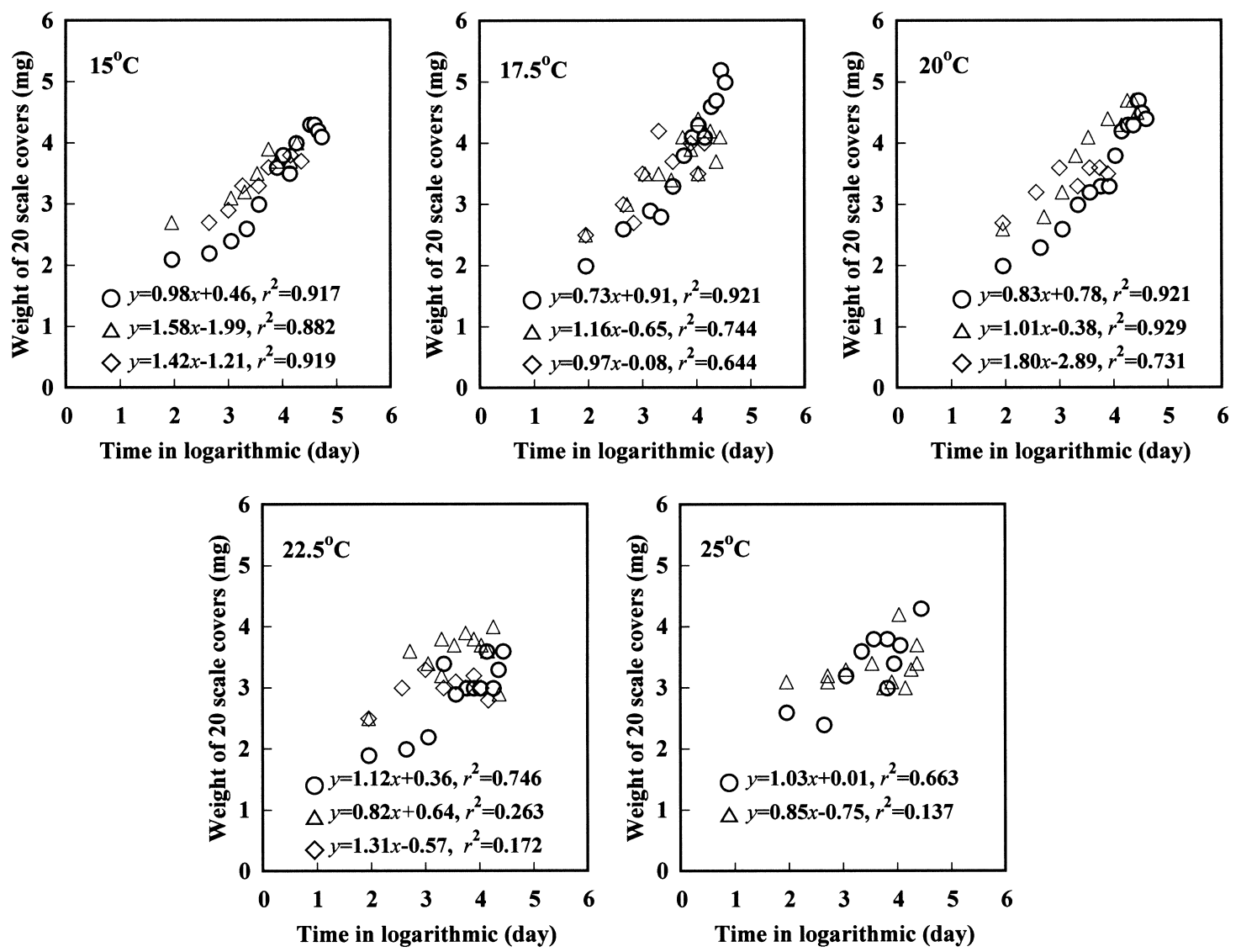

Fig. 3. The effects of temperature and time of transfer on the shell weight of $P$. pentagona females reared on pumpkin fruits. The females were transferred from natural conditions on November $22(\bigcirc)$, December $21(\triangle)$, December $28(\diamond)$ at 15 and $17.5^{\circ} \mathrm{C}$ and January $4(\diamond)$ at 20 and $22.5^{\circ} \mathrm{C}$.

According the meteorological data (1996 to 2004) for the study site, the number of days with a mean daily temperature below $15^{\circ} \mathrm{C}$ until the end of the year ranged between 53 and $68 \mathrm{~d}$ (mean, $59.3 \mathrm{~d}$ ). Temperatures ranging from 17.5 to $15^{\circ} \mathrm{C}$ might compensate for the lack of diapause development in warmer years so that winter diapause in most females ends by the end of the year.

The name "scale insects" derives from the commonly produced protective covering, or "scale". The scale covering may protect scale insects against water loss, excessively wet conditions, and attack by natural enemies including pathogens, and it may provide an attachment to the substrate (Gullan and Kosztarab, 1997). Scale insects, as sedentary animals, are heavily influenced by abiotic factors, and winter temperatures have a very important role, causing high mortality in the $P$. pentagona (Sheble and Kozar, 1996). The diapausing females of $P$. pentagona continuously fed on the pumpkin fruits and added secretory materials to the scale cover after being transferred from natural conditions, because there was a significant correlation between the weight of the scale covers and the rearing time (Fig. 3). No significant correlations between them were observed in the samples transferred to $22.5^{\circ} \mathrm{C}$ on December 21 and January 4, and to $25^{\circ} \mathrm{C}$ on December 21; females whose diapause was terminated might not add the secretory materials to the scale cover at higher temperatures. Although the weight of the scale cover might differ according to the diapause duration and environmental conditions, thick scale covers may reduce vulnerability to adverse environmental conditions in the females that overwinter for more than half of the year.

This study focused on the maintenance and termination of reproductive diapause in $P$. pentagona to enhance prediction of the optimal timing for chemical application using the effective temperature. Although there have been few studies on the induction of reproductive diapause in P. pentagona, 
reproductive diapause ends around the end of the year, and a starting date of January 1 is appropriate for the day-degree accumulations. Further study is needed to elucidate the effects of temperature and photoperiod on the induction of reproductive diapause in order to clarify the lifecycle adaptation of this insect.

\section{REFERENCES}

Danks, H. V. (1987) Insect Dormancy: An Ecological Perspective. Biological Survey of Canada, Ottawa. $439 \mathrm{pp}$.

Gullan, P. J. and M. Kosztarab (1997) Adaptations in scale insects. Annu. Rev. Entomol. 42: 23-50.

Hanks, L. M. and R. F. Denno (1993) The white peach scale, Pseudaulacaspis pentagona (Targioni-Tozzetti) (Homoptera: Diaspididae): life history in Maryland, host plants, and natural enemies. Proc. Entomol. Soc. Wash. 95: 79-98.

Kawai, A., A. Tatara and Y. Kozaki (1997) The outbreak of mulberry scale, Pseudaulacaspis pentagona (Targioni), at tea fields in Japan in 1994 and 1995. Tea Res. J. 85: 13-25 (in Japanese with English summary).

Nomura, M. and Y. Ishikawa (2000) Biphasic effect of low temperature on completion of winter diapause in the onion maggot, Delia antiqua. J. Insect Physiol. 46: $373-377$.
Park, J. D. and K. C. Kim (1990) Effects of temperature on development and distribution of mulberry scale, Pseudaulacaspis pentagona, within tree. Korean J. Appl. Entomol. 29: 238-243 (in Korean with English summary).

Sheble, D. A. F. and F. Kozar (1996) The winter mortality and developmental biology of Pseudaulacaspis pentagona Targioni-Tozzeti (Homoptera: Diaspididae). Acta Phytopathol. Entomol. Hung. 31: 45-51.

Shinano, K., T. Terada and M. Imanishi (1976) On the factor of the frequency of generation of mulberry scale Pseudaulacaspis pentagona (Targioni) parasitic on tea plants. Bull. Nara Exp. Sta. 7: 47-52 (in Japanese with English summary).

Takeda, M. (2004) Effects of temperature on oviposition in overwintering females and hatch in first-generation larvae of Pseudaulacaspis pentagona (Hemiptera: Diaspididae). Appl. Entomol. Zool. 39: 15-26.

Tatara, A. (1999) Determination of optimum spraying time for chemical control of mulberry scale, Pseudaulacaspis pentagona (Targioni) (Hemiptera: Diaspididae) in tea fields. Japan Agric. Res. Q 33: 155-161.

Yasuda, S. (1981) Reproduction of Pseudaulacaspis pentagona Targioni (Hemiptera: Diaspididae). Jpn. J. Appl. Entomol. Zool. 25: 39-46 (in Japanese with English summary). 